\title{
Pancytopenia due to proguanil toxicity in a returning traveller with fever
}

\author{
Hetty Jolink • Jan den Hartigh • Leo G. Visser • \\ Cees van Nieuwkoop
}

Received: 22 February 2010 / Accepted: 29 March 2010/Published online: 21 April 2010

(C) The Author(s) 2010. This article is published with open access at Springerlink.com

\begin{abstract}
A patient known to have renal insufficiency was admitted to the hospital with fever and pancytopenia after returning from a trip to Mali. Pancytopenia was not caused by a tropical infection but was a side effect of atovaquone/ proguanil used as malaria chemoprophylaxis. High and prolonged detectable proguanil serum levels can result in bone marrow suppression in patients with renal insufficiency. This should be taken into account in a returning traveller with fever and pancytopenia.
\end{abstract}

Keywords Pancytopenia $\cdot$ Proguanil $\cdot$ Malaria .

Chemoprophylaxis $\cdot$ Renal insufficiency

To the Editor,

An increasing number of people with chronic diseases travel to malaria endemic areas. Atovaquone/proguanil (Malarone) $250 / 100 \mathrm{mg}$ is being used as one of the first choice agents for malaria chemoprophylaxis but is contraindicated in people with glomerular filtration rate (GFR) $<30 \mathrm{ml} / \mathrm{min}$.

We saw a 49-year old woman with diarrhoea, fever and pancytopenia after a 2-week trip to Mali. She was known to have hypertrophic cardiomyopathy and chronic renal insufficiency (estimated GFR $36-50 \mathrm{ml} \mathrm{min}^{-1} 1.73 \mathrm{~m}^{-2}$ ) for which she used carvedilol, lisinopril and furosemide. She developed abdominal cramps, watery diarrhoea and

H. Jolink $(\bowtie) \cdot$ L. G. Visser · C. van Nieuwkoop

Department of Infectious Diseases,

Leiden University Medical Center,

Leiden, the Netherlands

e-mail: h.jolink@lumc.nl

J. den Hartigh

Department of Pharmacology, Leiden University Medical Center, Leiden, the Netherlands fever 1 week after arrival in Mali. The symptoms arose 2 days after drinking water from a well. Four days after returning from Mali she presented in the emergency room with persisting diarrhoea, nausea and fever $\left(38.5^{\circ} \mathrm{C}\right)$. She was still taking atovaquone/proguanil as malaria prophylaxis. On admittance we saw a dehydrated, non-acutely illappearing patient with pulse rate $70 / \mathrm{min}$, blood pressure $120 / 70 \mathrm{~mm} \mathrm{Hg}$ and a temperature of $38.3^{\circ} \mathrm{C}$. Besides right lower quadrant tenderness, physical examination was unremarkable. Laboratory results revealed a pancytopenia (Hb $5.7 \mathrm{mmol} / 1$, MCV 90, leucocytes $2.5 \times 10^{9} / 1$, thrombocytes $80 \times 10^{9} / 1$ ). There were no signs of diffuse intravascular coagulation. No previous results of blood counts were available. Serum creatinin was $279 \mu \mathrm{mol} / \mathrm{l}$ (eGFR $17 \mathrm{ml}$ $\min ^{-1} 1.73 \mathrm{~m}^{-2}$ ).

The clinical diagnosis was gastroenteritis but leptospirosis, malaria, dengue and typhoid fever were also considered because of pancytopenia. Malaria thick smear and blood cultures were negative. She was rehydrated, and 2 days later she was treated with clarithromycin according to the fecal culture that grew Campylobacter jejuni. She recovered slowly, and after 2 weeks her hemoglobin level gradually increased to $8.9 \mathrm{mmol} / \mathrm{l}$, leucocytes to $5.6 \times 10^{9} / 1$ and thrombocytes to $150 \times 10^{9} / 1$. By exclusion, pancytopenia was ascribed to proguanil toxicity, likely because of deteriorated renal function by dehydration due to gastroenteritis. Afterwards, serum levels of proguanil were measured. The results are outlined in Fig. 1. The calculated half-life of proguanil was over $26 \mathrm{~h}$ being twice as long as in healthy subjects [1]. In addition, the CYP2C19 enzyme was genotyped as this is known to be involved in proguanil metabolism. The patient is heterozygotic for the defect $* 2$ allele of CYP2C19, which is associated with a mildly decreased metabolic capacity. This may have partly contributed to 
Fig. 1 Elimination curve of proguanil levels in the patient compared to elimination curve of healthy subjects [1]. Extensive metabolizers have normal metabolic capacity of

CYP2C19, a key enzyme involved in the metabolization of proguanil to cycloguanil. Poor metabolizers have decreased metabolic capacity of CYP2C19. The expected elimination curve of the patient would be between the curves of poor and extensive metabolizers, but because of impaired excretion due to renal insufficiency the elimination curve is shifted to the right. $T=0$ : time of last tablet of atovaquone/proguanil

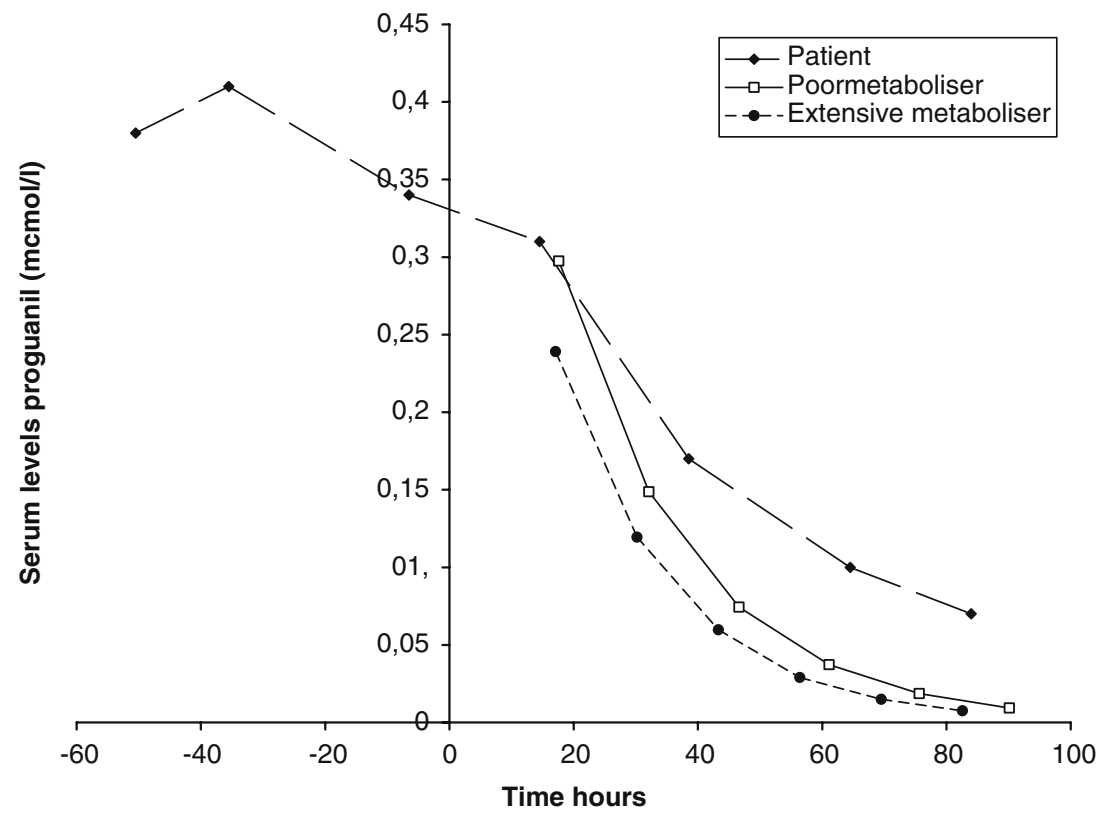

the prolonged elimination half-life of proguanil (Fig. 1), but not its toxicity [2].

Proguanil and its metabolite cycloguanil reduce the activity of the enzyme dihydrofolate reductase. This prevents the development of schizonts and inhibits the primary and secondary exo-erythrocytary forms of malaria [3]. In humans, the enzyme dihydrofolate reductase catalyzes the reduction of folic acid to dihydrofolate and tetrahydrofolate [4]. In healthy persons, proguanil levels are negligible for causing bone marrow suppression but sufficient for antimalarial activity as proguanil's affinity for the plasmodial enzyme is over 100 times greater than for the human enzyme [5]. However, high and prolonged detectable serum levels of proguanil and cycloguanil can also reduce the activity of the human enzyme causing depletion of intracellular tetrahydrofolate leading to anemia, leucopenia and thrombocytopenia. Proguanil is mainly metabolized by CYP2C19 to cycloguanil and 4chlorophenylbiguanide $[1,5]$. Both proguanil and cycloguanil are excreted by the kidneys and renal insufficiency is thus associated with proguanil toxicity [3]. Therefore atovaquone/proguanil is contraindicated in patients with a glomerular filtration rate $<30 \mathrm{ml} / \mathrm{min}$ [3].

The development of pancytopenia due to proguanil is rare. However, pancytopenia in a returning traveller with fever will usually be ascribed to the cause of the febrile illness and thus the possibility of proguanil toxicity might be overlooked. With increasing numbers of travellers with coexisting conditions, such as renal insufficiency, going to malaria endemic areas, hematologic side-effects of proguanil might arise more frequently.

Based on this case history, we recommend such chemoprophylaxis should be discontinued once a traveller presents with pancytopenia. In addition, this case highlights the importance of pre-travel counselling in subjects with renal insufficiency especially once travellers' diarrhoea occurs.

Open Access This article is distributed under the terms of the Creative Commons Attribution Noncommercial License which permits any noncommercial use, distribution, and reproduction in any medium, provided the original author(s) and source are credited.

\section{References}

1. Thapar MM, Ashton M, Lindegårdh N et al (2002) Time-dependent pharmacokinetics and drug metabolism of atovaquone plus proguanil (Malarone) when taken as chemoprophylaxis. Eur J Clin Pharmacol 58:19-27

2. Kerb R, Fux R, Morike K et al (2009) Pharmacogenetics of antimalarial drugs: effect on metabolism and transport. Lancet Inf Dis 9:760-774

3. McKeage K, Scott L (2003) Atovaquone/proguanil: a review of its use for the prophylaxis of Plasmodium falciparum malaria. Drugs 63(6):597-623

4. Fowler B (2001) The folate cycle and disease in humans. Kidney Int 59(suppl 78):S221-229

5. Thorogood N, Atwal S, Mills W et al (2007) The risk of antimalarials in patients with renal failure. Postgrad Med J 83 (986):e8 